\title{
Recursos ambientais e dinâmica populacional no semi-árido Paraibano
}

\author{
Ricardo Schmidt Filho ${ }^{1}$
}

Lúcia Maria Góes Moutinho²

\begin{abstract}
Resumo: Este trabalho trata dos conflitos distributivos do solo e da água e dos impactos socioeconômicos e ambientais no semi-árido paraibano. Um dos objetivos é entender as políticas de reforma agrária e de irrigação como elemento de controle dos fluxos populacionais. A metodologia utilizada é a do estudo de caso dos projetos de irrigação de Condado e de Santa Helena. As técnicas utilizadas foram: pesquisa direta (questionários e entrevistas) e pesquisa indireta (levantamento bibliográfico, dados secundários) realizadas entre os meses de outubro e dezembro de 2003. O trabalho está organizado em cinco seções: introdução; metodologia; conflitos sociais e as políticas de reforma agrária e de irrigação no Nordeste e na Paraíba; caracterização das áreas estudadas e os conflitos sociais locais. Os principais resultados alcançados na pesquisa apontam para: a) concentração fundiária e hídrica nos dois casos estudados; b) má-distribuição dos recursos (hídrico e solo), que penalizam a área estudada social e economicamente, através de processos de degradação ambiental e de êxodo rural; c) incremento do grupo de risco nas periferias de grandes cidades, receptoras dos retirantes do semi-árido paraibano devido à alocação ineficiente dos recursos ambientais disponíveis nas áreas estudadas. Um resultado inusitado foi o de que um pequeno número de retirantes encontrou espaço no mercado formal de trabalho.
\end{abstract}

Palavras-chave: dinâmica populacional; recursos ambientais; grupos de risco; políticas públicas.

\section{Natural resources and population dynamics in the semi-arid region of Paraíba State}

Abstract: This paper is about the conflict originated by the water and land division and its impacts on the economy and environment of the central region of Paraiba State. It overviews the state policies involving land reform and irrigation

\footnotetext{
1 Doutorando em Desenvolvimento Econômico (UFPR). Bolsista CAPES. E-mail: rschmidtfilho@hotmail.com.

2 Professora do Departamento de Economia e da pós-graduação em Economia da UFPB. E-mail: luma121@hotmail.com.
} 
SCHMIDT FILHO, R. \& MOUTINHO, L. Recursos ambientais e dinâmica populacional...

as an element to control population flows. The methodology chosen was to study irrigation projects in the cities of Condado and Santa Helena by means of investigation in loco (questionnaires and interviews) and of indirect analysis done between October and December of 2003. The paper is organized in five sections: introduction, methodology, social conflicts and public politics involving agrarian reform and irrigation at Northwest Region and at State of Paraiba; characterization of the regions studied and the local's social conflicts. The main conclusions in this paper indicate that: a) there is water and land concentration in both cities studied; $b$ ) those regions suffer social and economic consequences as a reflection of environmental degradation and emigration; c) there is a negative effect linking inefficient allocation of naturals resources, available at the areas studied, and the growth of the risk groups on the outskirts of big cities, where people emigrating from the central region of Paraiba go to; d) a small number of those people have found a job in the formal labor market.

Key-words: population dynamism, natural resources, risk groups, public policy

JEL: J18, J43, Q13.

\section{Introdução}

As experiências históricas demonstram que o desenvolvimento das sociedades tem levado ao esvaziamento do campo. Nesse sentido, no contexto brasileiro o Estado da Paraíba é o que vem apresentando as maiores taxas de decréscimo da população rural entre os estados do Nordeste nas últimas décadas, de acordo com Moura \& Teixeira (1997). Os autores apontam ainda para a intensificação do êxodo rural na década de noventa e afirmam que, na Paraíba, isso foi mais expressivo nas mesorregiões cujas características de semi-aridez são mais marcantes nas quais predominava o sistema gado/algodão de uso do solo, enquanto na zona canavieira houve arrefecimento desse processo de esvaziamento.

O decréscimo da população rural leva à transferência de conflitos sociais do campo para os centros urbanos mais desenvolvidos, na medida em que a população migrante passa a se somar às camadas socialmente marginalizadas das cidades. No entanto, os problemas não se restringem exclusivamente à escassez de recursos naturais nas áreas de expulsão, mas, sobretudo, à má-distribuição e acessibilidade a esses recursos. E é nesse campo que os conflitos sociais encontram-se latentes.

A intensidade do fluxo migratório de uma região para outra na Paraíba, além de dar mostras da dimensão das forças de expulsão do meio rural para o urbano, está em relação direta com a intensidade de transferência dos conflitos sociais. A Tabela 1 quantifica esse fluxo. Os dados sobre os fluxos migratórios mostram quão significativas as forças centrífugas foram nas duas últimas décadas. Ressalte-se que a população rural da 
Paraíba era de 1.321 em 1980 e foi reduzida para 1.149 em 1991, chegando a 1.038 em 1996. Portanto, o declínio ocorreu a uma taxa de crescimento negativa de $1,3 \%$ a.a. no período $1980 / 91$ e de 2,0\% a.a. entre $1991 / 96$.

No que diz respeito às microrregiões, como se pode ver na Tabela 1 , das vinte e três microrregiões do Estado, apenas seis (Patos, Curimataú Oriental, Litoral Norte, Guarabira, João Pessoa e Cariri Oriental) experimentaram uma diminuição no ritmo de decréscimo do contingente rural de sua população - valendo destacar que João Pessoa reverteu essa tendência na década de oitenta). Portanto, acentuou-se o problema em cerca de $70 \%$ das microrregiões do Estado.

TABELA 1. PARAÍBA: TAXAS DE CRESCIMENTO DA POPULAÇÃO RURAL (1980-1996) E ESTIMATIVAS DO ÊXODO RURAL (1991-1996) POR MICRORREGIÕES

\begin{tabular}{lrrrr}
\hline \multirow{2}{*}{ Meso e Microrregiões } & \multicolumn{2}{c}{ Taxas de Crescimento } & Exodo Estimado 91/96 \\
\cline { 2 - 5 } & $\mathbf{1 9 8 0 / 9 1}$ & $\mathbf{1 9 9 1 / 9 6}$ & Freq. Abs. & Freq. Rel. \\
\hline MATA PARAIBANA & $-0,7$ & $-0,6$ & 16.483 & 8,49 \\
Litoral Norte & $-0,9$ & $-0,8$ & 6.224 & 3,21 \\
Litoral Sul & 0,5 & $-0,2$ & 2.523 & 1,3 \\
João Pessoa & $-0,4$ & 0,7 & 1.006 & 0,52 \\
Sapé & $-1,4$ & $-1,6$ & 6.730 & 3,47 \\
AGRESTE PARAIBANO & -1 & $-1,7$ & 69.759 & 35,94 \\
Curimataú Oriental & $-1,2$ & $-0,6$ & 5.606 & 2,89 \\
Brejo Paraibano & $-1,4$ & $-2,4$ & 13.962 & 7,19 \\
Campina Grande & $-0,2$ & -1 & 10.392 & 5,35 \\
Curimataú Ocidental & $-1,5$ & $-4,2$ & 13.081 & 6,74 \\
Esperança & $-0,4$ & $-1,2$ & 2.908 & 1,5 \\
Guarabira & $-1,9$ & $-1,5$ & 8.832 & 4,55 \\
Itabaiana & -1 & $-1,2$ & 7.234 & 3,73 \\
Umbuzeiro & $-0,3$ & -2 & 7.743 & 3,99 \\
BORBOREMA & $-1,8$ & $-2,4$ & 26.748 & 13,78 \\
Cariri Oriental & $-0,7$ & $-1,1$ & 4.793 & 2,47 \\
Cariri Ocidental & $-2,5$ & $-2,4$ & 10.540 & 5,43 \\
Seridó Ocidental & -3 & $-7,6$ & 5.826 & 3 \\
Seridó Oriental & $-1,1$ & $-1,7$ & 5.590 & 2,88 \\
SERTÃO PARAIBANO & 1,5 & $-2,8$ & 81.129 & 41,79 \\
Cajazeiras & $-1,2$ & $-1,7$ & 11.795 & 6,08 \\
Catolé do Rocha & -2 & $-2,6$ & 15.718 & 8,1 \\
Itaporanga & $-1,5$ & -3 & 10.116 & 5,21 \\
Patos & $-2,7$ & $-1,1$ & 3.151 & 1,62 \\
Piancó & 1,7 & $-3,7$ & 10.569 & 5,44 \\
Sousa & -2 & $-2,1$ & 13.274 & 6,84 \\
Teixeira & $-0,3$ & $-3,2$ & 16.507 & 8,5 \\
PARAÍBA & $-1,3$ & $-1,9$ & 194.119 & 100 \\
\hline FONTE. Targino \& & & & &
\end{tabular}


SCHMIDT FILHO, R. \& MOUTINHO, L. Recursos ambientais e dinâmica populacional...

As maiores taxas de decréscimo da população rural são observadas em nove das onze microrregiões localizadas nas mesorregiões da Borborema e do Sertão Paraibano. Elas apresentaram uma taxa média de decréscimo populacional superior à média estadual, com destaque para a microrregião do Seridó Ocidental, cuja população rural foi reduzida ao ritmo de 7,6\% a.a. no período 1991/96. Ressalte-se que são essas microrregiões que apresentam os maiores aumentos nas taxas de deslocamento populacional entre os dois períodos estudados, sendo as que mais contribuíram para a intensificação do êxodo rural no período $1991 / 1996$.

Por terem experimentado acentuado declínio da população rural durante a década de setenta em decorrência da expansão canavieira, as microrregiões localizadas na mesorregião da Mata Paraibana apresentaram declínio menos acentuado na primeira metade dos anos noventa.

Segundo Targino \& Moreira (2000), os valores da estimativa de êxodo rural, revelam que:

a) em um espaço de apenas 5 anos, o êxodo rural estimado representa quase dois décimos da população rural do Estado, segundo a contagem da população de 1996, o que evidencia a intensidade do processo migratório na zona rural da Paraíba;

b) a distribuição do êxodo segundo as mesorregiões mantém uma relação diretamente proporcional à distribuição da população rural. Isto é, as mesorregiões que mais contribuíram para a formação do estoque de migrantes foram as do Agreste (35,94\%) e as do Sertão Paraibano (41,8\%) - justamente as que abrigam os maiores contingentes de população rural no Estado (39,6\% e $32,9 \%$, respectivamente).

c) quando se observa a relação êxodo estimado/população rural, que pode ser considerada como um indicador da intensidade migratória, constata-se que os mais altos valores desse indicador são obtidos nas mesorregiões do Sertão Paraibano $(23,64 \%)$ e da Borborema (20,9\%) e os mais baixos valores nas do Agreste $(16,9 \%)$ e da Mata Paraibana (10,7\%). Ressalte-se que esses resultados são o contrário dos apresentados para a década de oitenta, quando a maior intensidade migratória havia sido registrada na Mata Paraibana e, em segundo lugar, no Agreste Paraibano.

Na tentativa de encontrar explicações para as tendências identificadas, os autores levantaram hipóteses a respeito da organização agrária, tais como: 
SCHMIDT FILHO, R. \& MOUTINHO, L. Recursos ambientais e dinâmica populacional...

a) a praga do bicudo teria provocado a desestruturação do sistema gado/algodão, afetando de modo particular o nível de sua monetarização e as relações de trabalho em vigor, levando ao esvaziamento do campo;

b) tal dinâmica teria sido reforçada pela crise da pecuária regional, em decorrência da seca de 1993 que castigou fortemente o semi-árido paraibano;

c) a luta pela permanência na terra, mais intensa no litoral e em áreas açucareiras do Agreste, desencadeou o processo de reforma agrária, o que teria garantido não só a permanência como possibilitado, também, o retorno de grupos de trabalhadores ao campo;

d) as migrações sazonais dos trabalhadores rurais do Agreste para o trabalho na atividade canavieira na Zona da Mata ou para o trabalho na construção civil teriam favorecido, também, a permanência de suas famílias no campo, reduzindo o processo de evasão da população rural.

Como pode ser observado, na base dos processos migratórios os fatores de atração dos centros urbanos não necessariamente aparecem ao lado de fatores de expulsão do campo. Entre os mais diversos fatores de expulsão do homem do meio rural, o fenômeno das secas e a mádistribuição dos recursos territoriais e hídricos estão presentes e merecem ser ressaltados, pois reforçam os processos de redução da demanda de mão-de-obra para os trabalhos agrícolas.

Conforme Singer (1976), o processo migratório rural não pode ser entendido plenamente se for reduzido ao âmbito individual. Os aspectos estruturais e os conflitos distributivos são fundamentais para uma discussão desse processo. Nessa perspectiva, este artigo procura identificar alguns conflitos sociais relacionados à dotação e à distribuição de terra e de recursos hídricos como determinantes importantes da dinâmica populacional do semi-árido paraibano. Ao mesmo tempo avalia os resultados da atuação dos governos Estadual e Federal, através de seus projetos de irrigação, como instrumento de contenção desses conflitos.

\section{Metodologia}

A técnica de investigação utilizada neste trabalho é a do estudo de caso. A Paraíba foi o Estado do Nordeste escolhido para este estudo porque, 
SCHMIDT FILHO, R. \& MOUTINHO, L. Recursos ambientais e dinâmica populacional...

em relação aos demais estados da região, é o que apresenta maior percentual de área geográfica no chamado polígono da seca ${ }^{3}$.

Este artigo trata dos casos específicos de dois projetos de irrigação, o projeto de Santa Helena e o de Condado, não só por estarem localizados na bacia fluvial de maior representatividade da Paraíba, mas, principalmente, por permitirem maior visibilidade da ação pública na problemática da fixação do homem na terra. Trata-se de projetos concebidos e executados por duas esferas distintas de governo, a estadual e a federal, respectivamente.

Além dos procedimentos metodológicos acima citados, foi feito o levantamento de dados junto aos órgãos federais e estaduais responsáveis pelas políticas de irrigação - como o Departamento Nacional de Obras Contra as Secas (Dnocs), a Secretaria de Agricultura, Irrigação e Abastecimento (SAIA), a Secretaria Extraordinária de Meio Ambiente e Recursos Hídricos (Semarh) e, por fim, a Fundação Instituto Brasileiro de Geografia e Estatística (Fibge). O trabalho está organizado em mais três seções além da introdução e da metodologia. Quais sejam: 1) Conflitos sociais e as políticas de reforma agrária e de irrigação no Nordeste e na Paraíba; 2) caracterização das áreas irrigadas estudadas e os conflitos sociais locais e, 3) principais resultados.

\section{Conflitos sociais e as políticas de reforma agrária e de irrigação no Nordeste e na Paraíba}

Na base dos processos migratórios encontram-se conflitos latentes que, num primeiro momento, surgem relacionados à escassez de terra e de água e, em seguida, aparecem como uma questão distributiva. Para melhor compreendermos essa problemática, esta seção se ocupará primeiro das questões relativas à terra e, em seguida, abordará os conflitos relacionados à água.

\subsection{Estrutura fundiária e reforma agrária no Nordeste}

A lógica do processo de apropriação e de utilização da terra no Brasil levou à constituição de latifúndios dedicados à produção de culturas ou de pecuária comercializáveis e de minifúndios dedicados à produção de subsistência.

3 O Polígono das secas é a área geográfica que abrange os Estados de Alagoas, Bahia, Ceará, Minas Gerais, Paraíba, Pernambuco, Piauí, Rio Grande do Norte e Sergipe, caracterizada pelas repetidas crises de prolongamento das estiagens. Diferentes zonas geográficas constituem o polígono das secas, apresentando desta forma com distintos índices de aridez 
A monocultura da cana-de-açúcar foi mais acentuada no Nordeste devido às condições climáticas, à potencialidade do solo e ao relevo plano, que facilitou o manuseio da colheita. Essa monocultura, antes escravista, já embutia as características de uma exploração capitalista.

Somados à monocultura da cana-de-açúcar estavam os grandes latifúndios pecuários, responsáveis pela ocupação do interior da região, seguidos pela cultura do algodão e depois pela do fumo, sempre mantendo a característica de concentração da propriedade da terra. Ainda hoje, essa é uma das características da organização agrária regional, como pode ser observado na Tabela 2 a seguir.

TABELA 2. NORDESTE: ESTRUTURA FUNDIÁRIA - 1995/96

\begin{tabular}{|c|c|c|c|c|c|c|}
\hline \multirow[b]{2}{*}{ Grupos de área } & \multicolumn{3}{|c|}{ Número de estabelecimentos } & \multicolumn{3}{|c|}{ Área ( em hectares) } \\
\hline & $\begin{array}{l}\text { Freq. } \\
\text { Abs. }\end{array}$ & $\begin{array}{l}\text { Freq. } \\
\text { Rel. }\end{array}$ & $\begin{array}{l}\text { Freq. } \\
\text { Acum. }\end{array}$ & Freq. Abs. & $\begin{array}{c}\text { Freq. } \\
\text { Rel. }\end{array}$ & $\begin{array}{l}\text { Freq. } \\
\text { Acum. }\end{array}$ \\
\hline Até 10 & 1.536 .270 & 67,13 & 67,13 & 4.060 .627 & 5,18 & 5,18 \\
\hline 10 a 20 & 223.349 & 9,75 & 76,87 & 3.019 .743 & 3,85 & 9,03 \\
\hline 20 a 50 & 257.446 & 11,25 & 88,13 & 7.933 .516 & 10,13 & 19,15 \\
\hline 50 a 100 & 123.577 & 5,40 & 93,53 & 8.322 .025 & 10,62 & 29,77 \\
\hline 100 a 500 & 111.596 & 4,88 & 98,30 & 22.177 .615 & 28,32 & 58.08 \\
\hline 500 a 1000 & 13.819 & 0,60 & 98,90 & 9.294 .835 & 11,87 & 69,94 \\
\hline 1000 a 5000 & 21.674 & 0,95 & 99,85 & 14.400 .195 & 18,39 & 88,35 \\
\hline 5000 a 10000 & 515 & 0,02 & 99,87 & 3.321 .023 & 4,24 & 92,59 \\
\hline 10000 a 100000 & 290 & 0,12 & 99,99 & 5.355 .748 & 6,84 & 99,48 \\
\hline 100000 e mais & 3 & 0,00 & 100,00 & 410.769 & 0,52 & 100,00 \\
\hline TOTAL & 2.288 .439 & 100,00 & & 78.296 .096 & 100,00 & \\
\hline
\end{tabular}

FONTE: Furtado (2002).

Algumas considerações importantes podem dar uma idéia geral da distribuição fundiária na região:

a) os estabelecimentos com até 10 hectares (1.536.270), que representavam $67,13 \%$ do total de estabelecimentos, possuíam uma área de (4.060.627 hectares), ou seja, 5,18\% da área total do Nordeste;

b) os com área superior a mil hectares compunham o,98\% do total de estabelecimentos, mas se apropriavam de $29,9 \%$ da área recenseada.

Comparando-se o que ocorre nos extratos superior e inferior dos grupos de área, conclui-se que a distribuição da terra encontra-se excessivamente concentrada, de acordo com os dados da tabela acima. De fato, quando se confronta o Índice de Gini - relacionado à renda - da região 
SCHMIDT FILHO, R. \& MOUTINHO, L. Recursos ambientais e dinâmica populacional...

Nordeste $(0,832)$ com o do Brasil $(0,802)$, constata-se que a distribuição de terras no Nordeste explica grande parte da pobreza rural. Essa informação fomenta o discurso da necessidade e da emergência de uma reforma agrária para redução da desigualdade no meio nordestino.

Observa-se que, embora as desapropriações em todos os estados da região Nordeste tenham avançado, isso não foi o suficiente para reduzir a pobreza no campo porque o número de famílias que necessitam de terra é bem maior do que aquele atendido pelo programa de reforma agrária do País. Entre os anos de 1995 e de 2000, por exemplo, foram criados 1.296 projetos de assentamentos em uma área desapropriada de 3.651.154 hectares de terra nos nove estados nordestinos, o que representa somente $4,6 \%$ do total da área dos estabelecimentos recenseada no período 1995/96. Foram beneficiadas 102.679 famílias (veja Tabela 3).

TABELA 3. AÇÃO FUNDIÁRIA NO NORDESTE (95/2000)

\begin{tabular}{|c|c|c|c|c|c|c|}
\hline \multirow[b]{2}{*}{ Grupos de área } & \multicolumn{3}{|c|}{ Número de estabelecimentos } & \multicolumn{3}{|c|}{ Área ( em hectares) } \\
\hline & $\begin{array}{c}\text { Freq. } \\
\text { Abs. }\end{array}$ & $\begin{array}{c}\text { Freq. } \\
\text { Rel. }\end{array}$ & $\begin{array}{l}\text { Freq. } \\
\text { Acum. }\end{array}$ & Freq. Abs. & $\begin{array}{c}\text { Freq. } \\
\text { Rel. }\end{array}$ & $\begin{array}{l}\text { Freq. } \\
\text { Acum. }\end{array}$ \\
\hline Até 10 & 1.536 .270 & 67,13 & 67,13 & 4.060 .627 & 5,18 & 5,18 \\
\hline 10 a 20 & 223.349 & 9,75 & 76,87 & 3.019 .743 & 3,85 & 9,03 \\
\hline 20 a 50 & 257.446 & 11,25 & 88,13 & 7.933 .516 & 10,13 & 19,15 \\
\hline 50 a 100 & 123.577 & 5,40 & 93,53 & 8.322 .025 & 10,62 & 29,77 \\
\hline 100 a 500 & 111.596 & 4,88 & 98,30 & 22.177 .615 & 28,32 & 58.08 \\
\hline 500 a 1000 & 13.819 & 0,60 & 98,90 & 9.294 .835 & 11,87 & 69,94 \\
\hline 1000 a 5000 & 21.674 & 0,95 & 99,85 & 14.400 .195 & 18,39 & 88,35 \\
\hline 5000 a 10000 & 515 & 0,02 & 99,87 & 3.321 .023 & 4,24 & 92,59 \\
\hline 10000 a 100000 & 290 & 0,12 & 99,99 & 5.355 .748 & 6,84 & 99,48 \\
\hline 100000 e mais & 3 & 0,00 & 100,00 & 410.769 & 0,52 & 100,00 \\
\hline TOTAL & 2.288 .439 & 100,00 & & 78.296 .096 & 100,00 & \\
\hline
\end{tabular}

FONTE: Furtado (2002).

No que se refere ao Estado da Paraíba, a Tabela 4 mostra como se encontra a estrutura fundiária paraibana de acordo com o Censo Agropecuário (1995/96). Os dados revelam um grande número de pequenos estabelecimentos, mas com área relativamente pequena. A maior parte da área permanece na posse de um pequeno número de proprietários, caracterizando a concentração fundiária da Paraíba. 
SCHMIDT FILHO, R. \& MOUTINHO, L. Recursos ambientais e dinâmica populacional...

TABELA 4. PARAÍBA: ESTRUTURA FUNDIÁRIA (1995 /96)

\begin{tabular}{lrrrr}
\hline \multirow{2}{*}{ Grupos de área } & \multicolumn{4}{c}{ Número de estab. por Área (em hectares) } \\
\cline { 2 - 5 } & $\begin{array}{c}\text { Freq. } \\
\text { Abs. }\end{array}$ & Freq. Rel. & \multicolumn{1}{c}{ Freq. } & Freq. Rel. \\
& 101.435 & 69,26 & 293.012 & 7,13 \\
\hline Até 10 & 15.954 & 10,89 & 212.006 & 5,15 \\
10 a 20 & 14.289 & 9,75 & 436.037 & 10,61 \\
20 a 50 & 6.597 & 4,50 & 448.399 & 10,91 \\
50 a 100 & 6.896 & 4,70 & 1.384 .232 & 33,68 \\
100 a 500 & 864 & 0,58 & 573.492 & 13,95 \\
500 a 1000 & 407 & 0,27 & 668.725 & 16,27 \\
1000 a 5000 & 10 & 0,006 & 59.432 & 1,44 \\
5000 a 10000 & 3 & 0,002 & 34.011 & 0,83 \\
10000 a 100000 & 146.455 & 100,00 & 4.109 .347 & 100,00 \\
TOTAL & \multicolumn{4}{c}{} \\
\hline
\end{tabular}

FONTE: Furtado (2002).

Quanto à estrutura fundiária da Paraíba, verifica-se que a distribuição de terra permaneceu concentrada durante o período 1995c/200o, sem alterações significativas, o que mostra que o impacto da reforma agrária foi mínimo.

Os assentamentos realizados na região não resultaram exclusivamente da iniciativa governamental; muitos deles se deveram aos movimentos sociais. Tais assentamentos foram importantes para que os programas de redistribuição de terras em todos os estados da Federação voltassem à atividade.

Dentre os movimentos sociais, três organizações de trabalhadores rurais destacaram-se entre os que mobilizaram o homem do campo para reivindicar a democratização e o acesso à terra, além de melhores condições de trabalho e salário: a Confederação Nacional dos Trabalhadores na Agricultura (Contag), a Comissão Pastoral da Terra (CPT) e o Movimento dos Trabalhadores Sem-Terra (MST). Esses movimentos fundamentam suas ações na certeza de que a reforma agrária, executada de forma correta, diminui a pobreza e cria novas oportunidades para o homem do meio rural. Vale ressaltar que não basta só distribuir terras, é preciso fornecer crédito e infra-estrutura para que os assentamentos sejam auto-suficientes no menor intervalo de tempo possível.

\subsection{A água no semi-árido do Nordeste e da Paraíba}

A questão da contenção dos fluxos migratórios vem passando, ao longo dos anos, por vários tipos de providências para reduzir os efeitos danosos da seca e as argumentações para justificá-las têm sido as mais varia- 
SCHMIDT FILHO, R. \& MOUTINHO, L. Recursos ambientais e dinâmica populacional...

das. A mais comum é a de que ao se viabilizar a oferta regional de alimentos abrem-se oportunidades de trabalho e gera-se renda, propiciando dessa maneira maiores dividendos sociais e econômicos. Contudo, surgem algumas questões: 1) o problema da região é de insuficiência, de má-distribuição ou de má-utilização da água?; 2) os esforços voltados para a irrigação do Nordeste e da Paraíba têm sido o melhor caminho de contenção do fluxo migratório?; e 3) que resultados foram alcançados através de projetos públicos de irrigação, federais e estaduais, nessas áreas?

Toda a região do semi-árido nordestino é caracterizada pela baixa e mádistribuição das precipitações pluviométricas - caso da Paraíba, onde de cada quatro anos um é de seca. A variação pluviométrica média oscila entre 700 e $800 \mathrm{~mm}$ anuais e a evaporação é em torno de $2000 \mathrm{~mm} /$ ano. O trópico semi-árido apresenta duas estações bem distintas, uma seca - o verão, na qual chove muito pouco, e outra úmida o inverno, cuja precipitação de chuvas varia de acordo com os limites mencionados acima, concentrando-se nos primeiros meses do ano (Carvalho 1988).

No Nordeste, os estados da Paraíba e do Ceará são os mais afetados pela seca porque $97,78 \%$ e $92,99 \%$, respectivamente, de seus territórios estão incluídos no polígono das secas, como nos mostra a Tabela 5 abaixo.

TABELA 5. NORDESTE - ÁREA TOTAL E ÁREA INTEGRANTE DO POLÍGONO DAS SECAS, SEGUNDO OS ESTADOS

\begin{tabular}{crrrr}
\hline $\begin{array}{l}\text { Unidade da } \\
\text { Federação }\end{array}$ & Área em Km2 & $\begin{array}{c}\text { Área incluída } \\
\text { no polígono }\end{array}$ & $\begin{array}{c}\text { \% da área } \\
\text { incluída no } \\
\text { polígono }\end{array}$ & $\begin{array}{c}\text { \% da área do } \\
\text { polígono }\end{array}$ \\
\hline PI & 250.019 & 207.019 & 82,50 & 23,60 \\
CE & 146.817 & 136.526 & 92,99 & 15,57 \\
RN & 53.010 & 48.031 & 90,60 & 5,49 \\
PB & 56.372 & 55.119 & 97,78 & 6,28 \\
PE & 98.281 & 87.484 & 80,01 & 9,97 \\
AL & 27.652 & 12.266 & 44,36 & 1,40 \\
SE & 21.994 & 10.395 & 47,26 & 1,19 \\
BA & 559.951 & 320.214 & 57,13 & 36,50 \\
TOTAL & 1.215 .011 & 877.051 & 72,18 & 100,00 \\
\hline
\end{tabular}

FONTE: Fibge - Anuário Estatístico do Brasil (1980).

A escassez de água no Nordeste, tema estudado ao longo da história da Superintendência de Desenvolvimento do Nordeste (Sudene), vem sendo descrita e amplamente documentada dada sua importância para a região. A variação pluviométrica conhecida como "seca" é a principal caracte- 
rística do Nordeste, considerando-se que essa região possui apenas $3 \%$ da água doce do país, $70 \%$ dos quais provêm do Rio São Francisco.

Não há dúvidas sobre as evidências. Contudo, há controvérsias quanto às soluções para os efeitos danosos da seca às populações dessas áreasproblema. A abertura de poços para o aproveitamento das reservas subterrâneas de água, a dessalinização das águas do mar, o tratamento e a posterior reutilização de águas de esgoto, a indução de chuvas ou a construção de açudes seriam soluções paliativas, quando não economicamente inviáveis, pois seriam insuficientes para atender à demanda regional.

Uma das soluções - geradora de conflitos entre as esferas de governo e presente na maioria das discussões e controvérsias acerca do tema, é a transposição das águas do Rio São Francisco. O projeto para a transposição prevê benefícios a oito milhões de nordestinos dos estados do Ceará, do Rio Grande do Norte, da Paraíba e de Pernambuco e a contenção de trezentos mil migrantes da área rural para as cidades e de um milhão de nordestinos que se deslocariam para outras regiões do país.

O projeto inicial foi desenvolvido pelo Departamento de Obras e Saneamento entre 1981 e 1985, sendo posteriormente refinado no Governo Fernando Henrique Cardoso através do Ministério da Integração. Em sua primeira fase, o projeto propunha a derivação de trezentos metros cúbicos de águas do rio por segundo e após sua reformulação adotou-se o princípio de uso mínimo das águas do "Velho Chico". Esse princípio consiste na retirada de um bilhão e meio dos noventa bilhões de metros cúbicos de água do rio através de dois eixos de canais adutores situados entre as barragens de Sobradinho e de Itaparica. Portanto, não seria feito um desvio grande das águas do rio; só uma pequena parte de seu volume seria usada.

Esse tema é delicado e existem argumentos fortes de ambos os lados. Através da imprensa falada e escrita alguns argumentos contrários ao projeto podem ser resgatados, tais como: a) existem alternativas menos dispendiosas e mais eficientes do que a transposição de um rio, a exemplo daquelas referidas no início desta seção; b) o projeto não é economicamente viável; c) não resolveria o problema de água no Nordeste por se tratar de uma solução temporária; d) o projeto é um instrumento político que beneficiaria apenas os grandes proprietários; e) a tentativa de resolver o problema da seca em determinados estados poderia piorar a oferta de água em outros.

Ao lado dessas críticas, pode-se encontrar argumentação contundente em Suassuna (2000), que relaciona três pontos importantes a serem considerados: a intensa evapotranspiração que existe no semi-árido; o consumo de energia elétrica necessário para alcançar o volume de água 
SCHMIDT FILHO, R. \& MOUTINHO, L. Recursos ambientais e dinâmica populacional...

pretendido; e, o terceiro e mais importante, a garantia de vazão do rio que assegure a geração de energia elétrica, navegação e irrigação em áreas potenciais.

Além desses problemas, o autor ressalta o alto custo da obra (US\$ 1,01 bilhão) e apresenta como solução alternativa mais viável a integração das bacias Tocantins/São Francisco, cujo orçamento é da ordem de US\$ 116 milhões.

Percebe-se que essa questão está longe de ser esgotada e, enquanto isso, as condições de vida das populações afetadas pela seca pioram.

Como vemos, no semi-árido nordestino há uma gama de possíveis "soluções" e de problemas que decorrem da seca e que estão atrelados à falta de políticas efetivas para combater suas causas e seus efeitos. Casos de sucesso poderiam proliferar em todo o semi-árido se o problema passasse dos fóruns de debates políticos para a esfera das ações. O fato é que existem áreas irrigadas bem-sucedidas - como as que se encontram às margens do Rio São Francisco, em Pernambuco, ou mesmo as de Baraúnas e Mossoró, no Rio Grande do Norte, entre outras, onde a seca não representa problema para a fruticultura de exportação. Essa melhoria relativa entre produção e produtividade pode vir acompanhada de aumento de postos de trabalho em algumas áreas e da melhoria da infra-estrutura e da base técnica, o que propiciaria ampliação do mercado.

Os casos de projetos de irrigação bem-sucedidos geram dúvidas no que se refere a sua sustentabilidade, atrelada, por sua vez, às condições de oferta e de uso dos recursos hídricos. A esse respeito, Calegas (1988) aponta para os seguintes efeitos indesejáveis, se não houver o manuseio correto dos processos de irrigação e de drenagem:

a) a depender do manejo da água e do tipo de solo, os processos de salinização e de erosão dos solos podem se acelerar, tornando-os praticamente imprestáveis para a agricultura, sendo bastante difícil e onerosa a sua recuperação;

b) haverá queda na fertilidade natural dos solos, principalmente quando cultivados intensamente;

c) haverá poluição ambiental (da água, do solo e do ar), decorrente do uso de defensivos agrícolas;

d) elevar-se-á o custo social do deslocamento de agricultores no caso de desapropriação de áreas para a instalação de grandes projetos. 
Segundo Calegas (1988), o custo da irrigação pública no Brasil é cerca de três vezes maior do que o custo médio da irrigação pública mundial. Diante disto, vale destacar que, fora os casos de sucesso amplamente estudados e divulgados, é necessário que se faça avaliação das demais experiências de irrigação nas áreas que após a implantação dos projetos foram completamente esquecidas, como as dos casos aqui analisados os projetos de Condado e de Santa Helena.

\section{Caracterização das áreas estudadas e os conflitos sociais locais}

O município de Condado tem uma área de 377 quilômetros quadrados, possui densidade demográfica de 17,2 habitantes por quilômetro quadrado e está localizado na microrregião de Sousa, mesorregião do Sertão Paraibano. No período 1991/2000, a população de Condado teve uma taxa média de crescimento anual de $-0,22 \%$, passando de 6.620 habitantes em 1991 para 6.495 em 2000. A taxa de urbanização cresceu 22,18\%, passando de 51,99\% em 1991 para 63,53\% em 2000.

No período 1991/2000, a taxa de mortalidade infantil do município diminuiu 14,63\%, passando de 64,53 (por mil nascidos vivos) em 1991 para 55,09 em 2000, e a expectativa de vida ao nascer cresceu 1,05 ano, passando de 6o,51 anos em 1991 para 61,56 em 2000, de acordo com o Atlas do Desenvolvimento Humano (PNUD 2003).

A mesma fonte aponta para o crescimento de $41,69 \%$ da renda per capita média do município - passando de R\$ 56,77 em 1991 para R\$ 80,44 em 2000. A pobreza, medida pela proporção de pessoas com renda domiciliar per capita inferior a $\mathrm{R} \$ 75,5 \mathrm{O}^{4}$, diminuiu $17,01 \%$ - passando de 79,3\% em 1991 para 65,8\% em 2000. A desigualdade cresceu: o Índice de Gini (relativo à renda) passou de o,48 em 1991 para 0,53 em 2000.

No período 1991/2000, de acordo com o referido Atlas, o Índice de Desenvolvimento Humano Municipal (IDH-M) de Condado cresceu 12,92\%, passando de 0,534 em 1991 para 0,603 em 2000. O fator que mais contribuiu para esse crescimento foi a Educação, com $63,6 \%$, seguido pela Renda, com $28,2 \%$ e pela Longevidade, $8,3 \%$.

Nesse período, o hiato de desenvolvimento humano (a distância entre o IDH do município e o limite máximo do IDH, ou seja, 1 - IDH) foi reduzido em $14,8 \%$. Se essa taxa de crescimento do IDH-M fosse mantida, o município levaria 30,1 anos para alcançar São Caetano do Sul (SP), 
SCHMIDT FILHO, R. \& MOUTINHO, L. Recursos ambientais e dinâmica populacional...

município com o melhor IDH-M do Brasil (o,919), e 18,6 anos para alcançar João Pessoa (PB), melhor IDH-M do Estado (o,783).

Em 2000, o Índice de Desenvolvimento Humano Municipal de Condado foi de 0,603. Segundo classificação do PNUD, o município está entre as regiões consideradas de médio desenvolvimento humano (IDH entre o,5 e o,8). No entanto, em relação a outros municípios do Brasil, Condado apresenta uma situação ruim: ocupa a $4600^{a}$ posição, com 83,5\% dos municípios em situação melhor e 16,5\% em situação pior ou igual a ele, de acordo com o Atlas do Desenvolvimento Humano (PNUD 2003).

Em relação aos outros municípios do Estado, Condado está em situação intermediária: ocupa a $84^{\mathrm{a}}$ posição, com $37,2 \%$ dos municípios em situação melhor e $62,8 \%$ em situação pior ou igual.

Segundo informações obtidas através de pesquisa de campo, o perímetro irrigado estadual de Condado possui 53 colonos e abrange uma área de 626 hectares, dos quais 281 se encontram em operação - $231 \mathrm{com}$ irrigação e 50 sem irrigação, portanto, operando parcialmente. Essa área tem sido explorada nos últimos anos (de 93 a 95 e de maio de 98 até 2003) através de poços amazonas. O açude Engenheiro Arcoverde, que abastece o perímetro, teve sua comporta para irrigação lacrada por ordem judicial.

Em novembro de 2002 houve liberação da água, mas, como havia necessidade de recuperar trechos da infra-estrutura de irrigação, principalmente dos canais secundários, a água não foi liberada para os assentados, o que repercutiu drasticamente na produção. Entre as culturas que atualmente são produzidas no projeto - mamão, goiaba, melão, feijão, milho, pimentão, melancia, acerola e maracujá, para ilustrar - a mais importante, a banana, foi a mais prejudicada.

O outro caso aqui analisado se refere à experiência de irrigação coordenada pelo Governo Federal - ao contrário do Projeto de Condado, dirigido pelo Governo Estadual. Trata-se do projeto de Santa Helena que terá sua análise precedida pelas informações relativas ao município onde está localizado.

O município de Santa Helena tem uma área de 209,7 quilômetros quadrados, possui densidade demográfica de 29,4 habitantes por quilômetro quadrado e está localizado na microrregião de Cajazeiras, mesorregião do Sertão Paraibano.

No período 1991/200o, a população de Santa Helena teve uma taxa média de crescimento anual de $0,08 \%$, passando de 6.127 habitantes em 1991 para 6.170 em 2000. Por outro lado, a taxa de urbanização 
cresceu 18,40\%, passando de 36,33\% em 1991 para 43,01\% em 2000, de acordo com o Atlas do Desenvolvimento Humano (PNUD 2003).

Ainda no período 1991/200o, a taxa de mortalidade infantil do município diminuiu $19,24 \%$, passando de 58,88 (por mil nascidos vivos) em 1991 para 47,55 em 2000, e a expectativa de vida ao nascer cresceu 1,76 ano, passando de 61,76 anos em 1991 para 63,52 em 2000.

A renda per capita média do município cresceu 48,25\%, passando de R\$ 63,13 em 1991 para R\$ 93,59 em 2000. A pobreza, medida pela proporção de pessoas com renda domiciliar per capita inferior a $\mathrm{R} \$ 75,50^{4}$, diminuiu 21,89\%, passando de 83,6\% em 1991 para 65,3\% em 2000. A desigualdade, medida pelo Índice de Gini, também diminuiu (PNUD 2003).

No período 1991/200o, o Índice de Desenvolvimento Humano Municipal (IDH-M) de Santa Helena cresceu 16,42\%, passando de 0,536 em 1991 para 0,624 em 2000. O fator que mais contribuiu para esse crescimento foi a Educação, com 64,4\%, seguido pela Renda, com 24,6\%, e pela Longevidade, com 11,0\%.

Nesse período, o hiato de desenvolvimento humano (a distância entre o IDH do município e o limite máximo do IDH, ou seja, 1 - IDH) foi reduzido em 19,0\%. Se essa taxa de crescimento do IDH-M fosse mantida, o município levaria 22,1 anos para alcançar o mais alto IDH-M do Brasil, que éo de São Caetano do Sul (SP), com (o,919), e 12,9 anos para alcançar o município paraibano com o melhor IDH-M do Estado (0,783), o de João Pessoa.

Em 2000, o Índice de Desenvolvimento Humano Municipal de Santa Helena foi de o,624. Segundo classificação do PNUD, o município está entre as regiões consideradas de médio desenvolvimento humano (IDH entre 0,5 e 0,8). Em relação aos outros municípios do Brasil, Santa Helena apresenta uma situação ruim: ocupa a $4231^{\mathrm{a}}$ posição, sendo que $76,8 \%$ dos municípios estão em situação melhor e 23,2\% estão em situação pior ou igual.

Em relação aos outros municípios do Estado, Santa Helena apresenta uma situação boa: ocupa a $46^{\mathrm{a}}$ posição, com 20,2\% dos municípios em situação melhor e 79,8\% em situação pior ou igual.

O projeto federal de irrigação, denominado Lagoa do Arroz, está localizado no Distrito de Várzea do Arroz e ainda não foi completamente implementado. Possui uma área de 800 hectares irrigados e é abastecido pelo açude também chamado de Lagoa do Arroz, que possui uma capacidade de armazenamento de 40 milhões de metros cúbicos de água. 
SCHMIDT FILHO, R. \& MOUTINHO, L. Recursos ambientais e dinâmica populacional...

Nesse projeto há 266 irrigantes e as principais culturas são o milho, o feijão, a banana, a goiaba, o algodão, o coco e o arroz.

Nesse caso, o conflito não acontece entre os colonos e o governo, mas, entre os grupos de colonos. O quadro de desorganização dos produtores que figurava em 1999 não é verificado atualmente, pois quase todos os produtores são vinculados à cooperativa local. Contudo, ocorre uma disputa entre os próprios irrigantes e sua cooperativa, motivada pela distribuição do uso do trator e do caminhão que foram adquiridos com recursos da cooperativa para fazer a distribuição dos produtos do perímetro nos mercados da circunvizinhança. Aparentemente, essas divergências não têm importância. Entretanto, elas vão além do uso dos bens de capital, pois a cooperativa compra a produção antecipadamente, pagando preços inferiores aos que os colonos obteriam através da venda direta no mercado. Portanto, a cooperativa atua em detrimento dos cooperados na medida em que beneficia seus líderes e provoca perda financeira aos demais.

\section{Resultados}

A política de irrigação é importante uma vez que incrementa a produção na região semi-árida e tem impacto sobre as relações de produção. Ao passar da agricultura de sequeiro para o regime de irrigação, transformam-se as relações de produção vigentes no campo. Cria-se um sistema distinto do regime tradicional de produção, como os de parceria e arrendamento, e, desse modo, novas relações de trabalho são necessárias, com ênfase no trabalho assalariado.

É sob essa ótica que se enfatiza a importância de políticas de irrigação para conter o êxodo rural no semi-árido paraibano. A adoção de tais políticas associada à política de distribuição de terras tende a melhorar e modernizar as condições de vida das populações. Ainda que as velhas relações de trabalho sejam retomadas, elas assumirão novos aspectos positivos ao apresentar maior grau de monetarização e maior interligação com o mercado. No entanto, o que se observa é que tanto a política de reforma agrária quanto a política de irrigação têm apresentado modestos resultados no semi-árido paraibano no que se refere à contenção dos fluxos migratórios ou mesmo dos conflitos sociais que certamente continuam latentes.

Com relação aos projetos Estadual e Federal no semi-árido paraibano, os resultados alcançados, na esfera sócio-econômica local, transparecem no Índice de Desenvolvimento Humano dos municípios em que os projetos foram implantados; Condado e Santa Helena encontram-se no grupo de municípios com os piores IDH do país. 
A pesquisa de campo, que retratou os cenários do semi-árido nordestino, aponta para a concentração fundiária e hídrica. Nesses casos, a mádistribuição dos recursos penaliza as áreas estudadas, social e economicamente, através de processos de degradação ambiental e de êxodo rural.

Uma informação inusitada obtida na pesquisa de campo foi a de que pequeno número desses retirantes encontra espaço no mercado formal de trabalho fora do Estado e envia apoio financeiro para a família, que continua no meio rural. No entanto, vale ressaltar que a maior incidência de migração acontece entre os jovens que, em sua maioria, não conseguem se inserir formalmente no mercado de trabalho, mesmo em ocupações de baixa remuneração e, por esse motivo, passam a ingressar nos grupos de risco nas periferias das grandes cidades. Essas evidências apontam para a falta de oportunidade de trabalho nos projetos, o que alimenta o processo de êxodo rural.

Os dois municípios estudados se encontram na mesorregião do Sertão Paraibano e seguem a tendência dessa região, apresentando um elevado índice de êxodo rural, contribuindo assim para o processo de crescimento exacerbado das populações urbanas de grandes cidades como Fortaleza, Campina Grande e João Pessoa, para ilustrar.

A tendência apresentada pela mesorregião do Sertão Paraibano ao longo da década de 90 e o incremento dos problemas relacionados ao êxodo de sua população estão ligados de maneira direta aos problemas hídricos e de concentração fundiária na Paraíba.

Como já foi ressaltado, a Paraíba é um Estado com sérios problemas hídricos, sendo o Estado do Nordeste que possui a maior participação relativa no polígono das secas. Esse fato, aliado à falta de políticas mais intensivas de irrigação e de reforma agrária, faz com que o problema do êxodo rural seja bem elevado na Paraíba, e mais especificamente na mesorregião do Sertão Paraibano. Assim sendo, as populações locais, frente às dificuldades do dia-a-dia - relacionadas ao cultivo (falta de terra e de água) e ao fato de grande parte da produção rural ser de base familiar não-remunerada, acabam por buscar melhores condições de vida na cidade grande.

Os casos de Condado e de Santa Helena foram escolhidos por estarem localizados em regiões atendidas por projetos de irrigação e com o intuito de se verificar se essa política pública tem amenizado o processo migratório nessas cidades. Constatou-se que as condições de vida melhoraram com a implantação dos perímetros irrigados. Contudo, devido ao fato de não haver uma política de crédito voltada para os agricultores locais, tampouco uma continuidade na implementação dos 
SCHMIDT FILHO, R. \& MOUTINHO, L. Recursos ambientais e dinâmica populacional...

projetos de irrigação (obra que se encontra parada), a tendência é de que a migração continue.

Também foi verificada mudança nas características do migrante. Anteriormente, era o líder familiar que partia para a cidade grande em busca de trabalho - geralmente ocupando postos de baixa remuneração e qualificação, como na construção civil, ou, então, partindo para o mercado informal - e deixava esposa e filhos no interior. Observava-se que as condições de vida enfrentadas por esses trabalhadores não eram boas e muitas vezes eram inferiores às que possuíam antes de migrarem, pois, mesmo diante de todas as dificuldades enfrentadas na região de origem, ao menos a subsistência era garantida. Muitos dos entrevistados afirmaram que não sonham mais em realizar suas vidas na cidade grande, pois a região de origem lhes permite condições de vida melhores que as alcançadas nos grandes centros urbanos. Desse modo, a migração passa a assumir novo caráter.

Atualmente, a migração é constituída de jovens que, desiludidos com a falta de perspectiva e de apoio na agricultura familiar praticada nas regiões de origem, partem para as grandes cidades em busca de melhores perspectivas de vida. Tendo em vista seus maiores níveis de escolaridade, são jovens que em grande parte possuem melhores condições de empregabilidade do que seus pais, já que entre os agricultores mais velhos o analfabetismo se faz mais presente.

Segundo dados coletados no Projeto de Condado, 87 dos 147 filhos de entrevistados dessa localidade migraram e, também, 57 dos 111, no caso de Santa Helena.

Essa tendência acentuada de migração dos jovens da região corrobora a alta média de idade apresentada pelos produtores rurais (59 anos), o que compromete a continuidade da produção do projeto. Portanto, a atividade agrícola não tem sido atrativa e esse fato tem impulsionado o fluxo migratório. Assim, mesmo enfrentando o inchaço das grandes cidades e o crescimento das taxas de desemprego urbanas, alguns dos jovens conseguem trabalho como porteiros, cabeleireiros, etc. Ou seja, entram para o mercado de trabalho formal e muitas vezes auxiliam na manutenção de suas famílias, que ficaram no campo.

Outro problema associado aos dois casos é o de que nenhum processo de assentamento nas terras foi realizado antes de os atuais projetos de irrigação serem implementados - as últimas tentativas de políticas nesse sentido são da década de 70. Assim sendo, no caso de Santa Helena, dos 60 entrevistados, 25 eram proprietários e 35 não o eram. Ainda, dos 25 proprietários, poucos realmente trabalhavam na terra; a maioria empregava rendeiros e parceiros para o cultivo. Além disso, há concentração das áreas cultivadas. Tanto as de sequeiro quanto as 
irrigadas estão concentradas nas propriedades de 5 produtores que, juntos, amealham $57,77 \%$ da área plantada. Isso mostra que existe uma concentração fundiária preocupante na região, causadora de problemas relacionados ao trabalho dos não-detentores de terras que se vêem reféns das vontades dos proprietários - tendo de arrendar as terras ou, então, de aceitá-los como parceiros, ou, ainda, de submeter-se aos contratos por diária. No caso de Condado também se verifica a concentração fundiária, mas essa não se dá de maneira tão enfática quanto a verificada em Santa Helena.

Um aspecto que cabe ser ressaltado, ainda é de que existe um problema social em estado latente na região, sem conflitos diretos entre a população e o governo, ou entre os próprios habitantes. Contudo, há disputas em torno do uso de máquinas - como tratores, nos dois casos aqui estudados e, também, acusações feitas por membros dos projetos de irrigação de que líderes da cooperativa estariam favorecendo a si próprios e a alguns produtores utilizando os recursos da instituição. Outro problema é que ambos projetos de irrigação estão com as obras paradas e, por essa razão, as terras mais próximas dos canais de irrigação do perímetro são beneficiadas, gerando acusações de que os favorecidos usariam mais do recurso que é destinado a todos, prejudicando assim os demais. De acordo com os produtores, as comportas que abastecem o canal que irriga o perímetro também são fechadas às vezes e as águas são destinadas para fins como o de abastecimento de açudes particulares de políticos da região. A versão oficial para tal fechamento é de que o nível de água do açude se encontra muito baixo, sendo necessário o fechamento. Percebe-se que apesar de os conflitos não aparecerem de forma clara, eles são sérios.

Assim sendo a conclusão final deste trabalho é a de que, mesmo diante de todos os esforços praticados pelos órgãos públicos, há falhas nas políticas de irrigação e de assentamento rural. Essas , portanto, não se têm mostrado suficientes para a manutenção da população em seu local de origem, apesar de terem proporcionado pequenas melhorias no nível de vida.

\section{Referências}

PNUD (2003). Atlas do Desenvolvimento Humano 2003. Brasília: PNUD; São Paulo: IPEA; Belo Horizonte: Fundação José Pinheiro.

CALEGAS, Geraldo M. (1988). “Contribuição da irrigação para a economia regional: o caso do Nordeste.” Revista Econômica do Nordeste 19 (1).

CARVALHO, Otamar de (1988). A economia política do Nordeste, secas, irrigação e desenvolvimento. Rio de Janeiro: Campus. 
SCHMIDT FILHO, R. \& MOUTINHO, L. Recursos ambientais e dinâmica populacional...

FURTADO, Acídio P. (2002). Política agrária e estrutura fundiária no Nordeste (1995 a 2000). João Pessoa, Monografia, Universidade Federal da Paraíba.

MOREIRA, E. \& TARGINO, I. (2000). "Êxodo rural na Paraíba: análise do período 1991/96.” In SANTOS, T. (org.). Dinâmica das Regiões Norte e Nordeste: questões atuais e emergentes. Recife: Massangana, pp.83-106.

MOURA, H. \& TEIXEIRA, P. (1997). "Tendências recentes do crescimento populacional." Estudos Avançados 11 (29): 95-126.

SINGER, Paul (1976). Economia política da urbanização. São Paulo: Brasiliense.

SUASSUNA, João (2000). “A gerência da torneira.” Revista Águaonline 3 (20), 26 abr.

Submissão: 11 de maio de 2007 Primeira resposta: 27 de julho de 2007 Aceite: 13 de agosto de 2007 